\title{
CHROMOSOME ABERRATIONS INDUCED IN CULTURED HUMAN CELLS BY CAFFEINE
}

\author{
SUNG LEE \\ Department of Anatomy, Faculty of Medicine, Kyoto University, Kyoto 606
}

Received July 20, 1971

Caffeine (1,3,7-trimethylxanthine) is suspect as a possible mutagen because of its purine nature. In view of our frequent contact with it in relatively large quantities in soft drinks, tea, and coffee, as well as in drugs, its possible mutagenicity presents a serious problem. The mutagenicity of caffeine has therefore been extensively tested in a wide variety of systems. The mutagenic effect of caffeine was first found in bacteria (Demerec et al. 1951; Novick and Szilard 1951; Gezelius and Fries 1952; Novick 1956). However, in higher organisms such as Drosophila and mouse, a large number of experiments have shown apparently conflicting results: an almost equal number of results have been accumulated for positive and negative mutagenicity as seen in the recent reviews by Adler (1970) and Epstein (1970). In contrast to such controversial findings in laboratory animals, all cytological examinations in human cell cultures have shown caffeine to be a powerful chromosome-breaking agent (Ostertag et al. 1956; Ostertag 1966; Ostertag and Greif 1967; Kuhlmann et al. 1968). These finding led Ostertag (1966) and Kuhlmann et al. (1968) to warn against caffeine as one of the most dangerous mutagens in man, and again emphasized the need for studies of its mutagenic effectiveness.

The present paper deals with the results of experiments with chromosomes of cultured human leucocytes and human embryonic cells exposed to caffeine. These experiments were carried out in an effort to reproduce the results of the earlier in vitro experiments, and the discussion includes some evaluation of caffeine-induced chromosome aberrations which are relevant to the results on the mutagenicity in laboratory animals.

\section{MATERIALS AND METHODS}

In the first series of experiments, types and rates of caffeine-induced chromosome aberrations were studied in cultured human leucocytes and embryonic fibroblasts. Human peripheral blood leucocytes from two healthy adults were cultured using a modification of Moorhead et al. (1960), and caffeine was added at final concentrations of $0.005,0.01$, $0.025,0.05$ and $0.1 \%$ for a period during the last 24 hours of the 72-hour culture, with the last 4 hours in the presence of colchicine. Fibroblast cultures were obtained from the kidney and lung tissues of two aborted embryos of 2.5 and 3.1 months of gestational age. When the cultures reached about $70 \%$ confluence, they were treated with caffeine in the same way as in the leucocyte cultures. The fibroblast cultures used in this experiment were confirmed to have a normal female karyotype. Air-dried preparations 
were stained with Giemsa and evaluated for the types and number of chromosome aberrations. In each experiment 50 to 200 cells were analysed.

In the second series of experiments, for understanding of the time and mode of origin of caffeine-induced chromosome aberrations in relation to the cell cycle, caffeine and ${ }^{3} \mathrm{H}$-thymidine $\left({ }^{3} \mathrm{H}\right.$-TdR, specific activity of $\left.24 \mathrm{Ci} / \mathrm{mM}\right)$ were added simultaneously to the leucocyte cultures in final concentrations of $0.1 \%$ and $0.5 \mathrm{uCi} / \mathrm{ml}$, respectively. Caffeine and ${ }^{3} \mathrm{H}-\mathrm{TdR}$ were added for 1 hour with various periods of recovery time. After treatment the cells were washed once with Hanks' BSS containing a $10^{-4} \mathrm{M}$ cold $\mathrm{TdR}$ and reincubated in freshly prepared culture medium containing $5 \times 10^{-5} \mathrm{M}$ cold TdR. The cells were fixed at 72 hours of total incubation time, the treatment being followed with colchicine for the last 2 hours of the incubation. Air-dried preparations were prepared, coated with Kodak NTB 2 nuclear track emulsion, exposed for 10 days and processed for autoradiography. Chromosome aberrations were scored in the unlabelled and labelled cells before and after removing silver grains. Some slides were not coated with emulsion but were stained directly, and chromosome aberrations were scored in unselected cells.

In the analys:s, chromatid gap refers to a clear simple discontinuity of one chromatid. When both chromatids in the same region were similarly affected, the aberration is referred to as an isochromatid gap. When the fragment was clearly dislocated, it was recorded as a chromatid break. Because of the difficulty of demarcation between them, isochromatid breaks were included in the acentric fragments.

\section{RESULTS}

In cultures treated with caffeine for 24 hours, unquestionable increase in the number of chromosome aberrations was observed. The chromosome aberrations were essentially of the chromatid type, including chromatid gaps, isochromatid gaps, chromatid breaks and acentric fragments. A significant feature of the caffeine-induced chromosome aberrations was the absence of exchanges. The relationship between the frequency of chromatid aberrations and the concentration of caffeine is presented in Fig. 1. As seen in this figure, there was no difference between the responses of cultured leucocytes and embryonic fibroblasts in culture. In control cultures which were not treated with caffeine and otherwise processed in the same way, the frequency of chromatid aberrations was less than 0.1 per cell. The number of aberrations per cell increased with the increase of the caffeine dose in the low-dose range, but in the high-dose range the increasing rate of aberrations leveled off progressively. Thus, the dose-response relation of the aberration frequency was not simple, but it was obvious that caffeine of as low as $0.005 \%$ was effective enough to double the level of such aberrations over the level of the controls. Fig. 2 shows the results of experiments in which the sensitivity of the cells to caffeine was determined at different parts of the cell cycle. With recovery times of $7,12,17$ and 21 hours, all the labelled cells had chromosomes with both chromatids labelled, whereas in the preparations made 25 and 29 hours after treatment there appeared the labelled cells in which only one sister chromatid was labelled, indicating that they had been exposed to caffeine in the DNA-synthesis phase of the preceding cell 


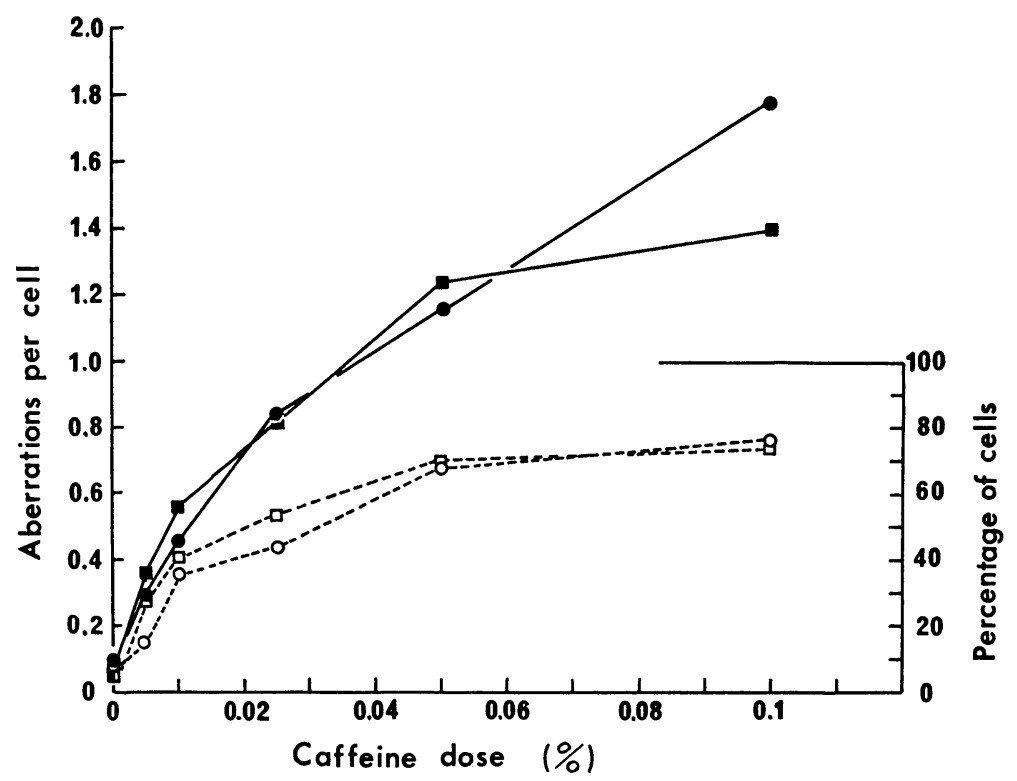

Fig. 1. Relationship between frequency of chromatidaberrations and concentration of caffeine. Circles: cultured human leucocytes. Squares: human embryonic fibroblasts in culture. Solid Symbols represent number of chromatid aberrations per cell, and open symbols show percentages of the cells with these aberrations.

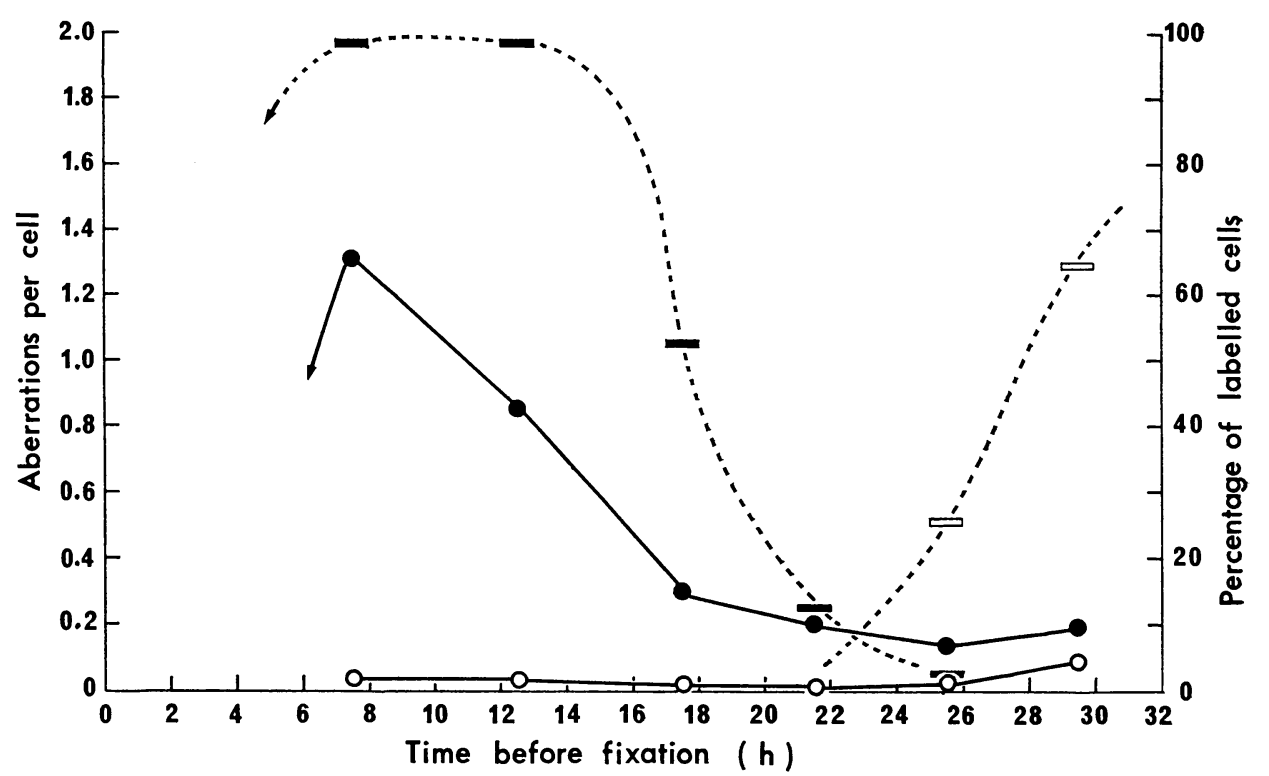

Fig. 2. Frequency of chromosome aberration induced by caffeine $(0.1 \%)$ in relation to the cell cycle. Solid circles: chromatid aberrations per cell. Open circles: chromosomal aberrations per cell. Rectangles represent percentages of the labelled celles (solid symbols: both chromatids labelled; open symbols: single chromatid labelled). 
cycle and therefore they were in the second mitosis after exposure. Judging from the labelling indices, the time required for $S$ plus $G_{2}$ phase was about 18 hours which indicated that the 1 hour $0.1 \%$ caffeine treatment did not greatly affect the cell cycle. The frequency of chromatid aberrations was highest in cultures treated in late $\mathrm{S}$ phase and gradually decreased with the increase of the post-exposure recovery time. Chromosomal aberations were less frequent all through these experiments. A slight increase in the chromosomal aberrations, which included acentric fragments and abnormal monocentrics, was found only in cultures at terminal rocovery time of 29 hours.

In order to observe more details of stage sensitivity, chromosome aberrations were scored separately in labelled and unlabelled cells. Unlabelled cells from the population which had been exposed to ${ }^{3} \mathrm{H}-\mathrm{TdR}$ were selected as representative of $\mathrm{G}_{1}$ and $\mathrm{G}_{2}$ cells. These were collected at recovery times of 7 and 17 hours after exposure to ${ }^{3} \mathrm{H}$ - TdR for representation of $G_{2}$ and $G_{1}$ phases respectively. For late $S$, mid $S$ and early $S$ phase, labelled cells were selected at recovery times of 7,12 and 17 hours respectively. The effectiveness of caffeine in different phases of the cell cycle is presented in Fig. 3 . The frequency of chromatid aberrations in cells which were exposed to caffeine in the $\mathrm{S}$ phase of the preceding cell cycle is also presented for comparison. In these cells, the frequency of chromatid aberrations was slightly higher than that observed in cells exposed at $G_{1}$ and $G_{2}$ phase, though the difference was not significant. The results of the present experiments revealed that caffeine-induced breaks only during $\mathrm{S}$ phase, since treatment of cells at $G_{1}$ and $G_{2}$ phases did not seem to show caffeine-induced breaks. The later part of $\mathrm{S}$ phase was the stage most sensitive to the induction of chromosome aberrations. The karyotype analysis was made in cells which were exposed to caffeine in the S phase of the preceding cell cycle and thus in their second mitosis after exposure. Out of 100 cells analysed, 72 had a normal karyotype, while 12 showed simple loss of one to three chromosomes without any general tendency of missing particular chromosomes. Of particular interest in the remainder was the occurrence of a relatively

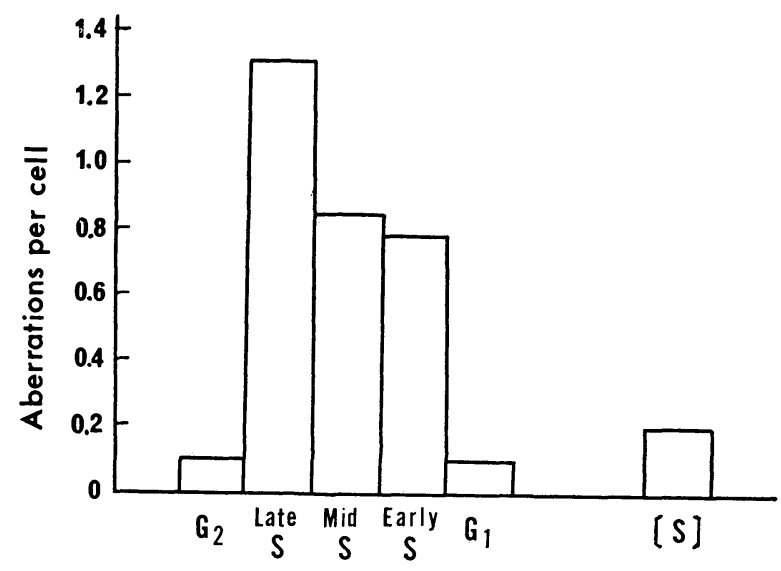

Fig. 3. Comparison of stage sensitivity of chromosome-breaking effect of caffeine. DNA-synthesis phase in the preceding cell cycle is presented by $[\mathrm{S}]$. 
Table 1. Types and frequencies of cells with abnormal chromosome constitution, exposed to caffeine in the $\mathrm{S}$ phase of the preceding cell cycle

\begin{tabular}{cc}
\hline Types of chromosome aberrations & No. of cells \\
\hline Normal Karyotype & 72 \\
Simple loss* & 12 \\
Extra chromosome & 1 \\
Acentric fragment & 12 \\
Terminal deletion & 3 \\
\hline Total & 100 \\
\hline
\end{tabular}

*Random loss of one to three chromosomes.

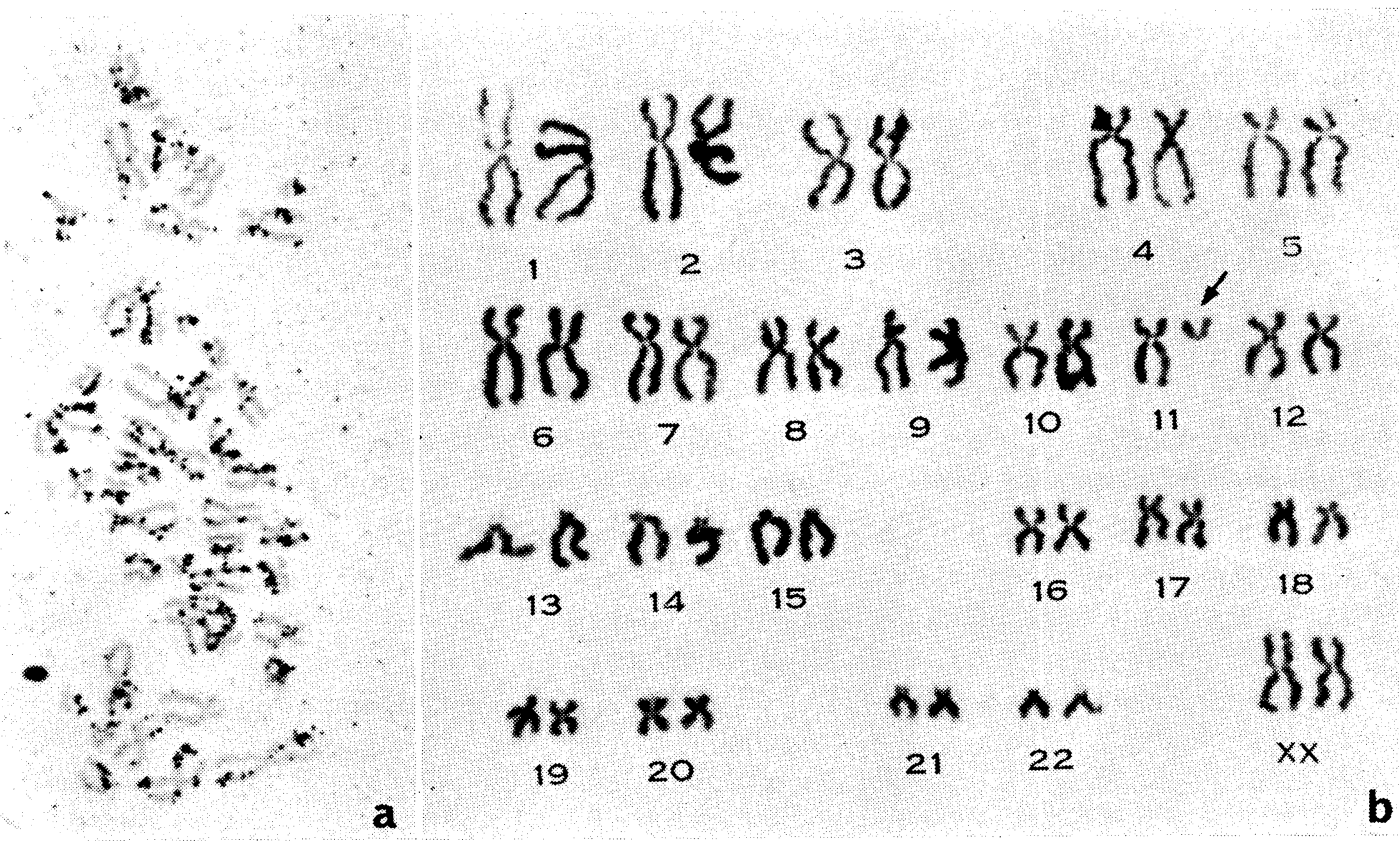

Fig. 4. Autoradiogram and karyotype of a cell exposed to caffeine in the S phase of the preceding cell cycle. The cell (arrow) shows a terminal deletion in a chromosome of group $\mathrm{C}(46, \mathrm{XX}, \mathrm{Cq}-)$.

large number of cells with aberrant chromosomes such as an extra minute chromosome, acentric fragments, and terminal deletions (Table 1). An example of simple terminal deletions was shown in Fig. 4. Since chromatid aberrations were so infrequent in this group of cells, these aberrations were considered as derived from chromatid aberrations occurring in their first mitosis after exposure.

\section{DISCUSSION}

The present experiments showed that caffeine unqestionably induced chromosome aberrations in cultured human cells. The findings were essentially similar to those of 
Ostertag et al. (1965), Ostertag (1966), and Ostertag and Greif (1967), in that the induced chromosome aberrations were of the chromatid type, mostly chromatid gaps and chromatid breaks, and that exchange aberrations were very rare. In the experiments with HeLa cells which were analysed 24 hours after 1 hour exposure, Ostertag et al. (1965) found that the number of aberrations increased almost linearly with the dose. However, in the present experiments, in which caffeine was present for the last 24 hours, the aberration rate did not linearly increase in the high-dose range, and there was no simple, obvious dose relationship between number of aberrations and caffeine dose. This may be due to the inhibitory effects of high concentrations of caffeine on the cell's ability to progress through mitosis.

Since caffeine induces chromatid aberrations, it seems reasonable to assume that caffeine-induced aberrations, regardless of where the primary damage originates, can be realized only during the first DNA synthesis period which follows exposure. However, for understanding its mode of action, and the types of tissues and the stages of development which display a maximum risk of aberrations, it is important to know the location of the damage in relation to the cell cycle. From the experiments with HeLa cells and cultured human leucocytes on the effects of the interim between the treatment and fixation on aberration yield, Ostertag (1966) and Ostertag and Greif (1967) reported that aberrations were most frequent if the cells were treated in middle and late $G_{1}$ phase, but low in the late $S$ phase. These findings contradict the present results regarding stage sensitivity, which were obtained from the analysis of cells selected on the basis of the ${ }^{3} \mathrm{H}$-TdR labelling pattern. In the present experiments, the sensitive stage was confined to the DNA-synthesis phase, in which the later part of the $S$ phase was the most sensitive. Treatment in $\mathrm{G}_{1}$ and $\mathrm{G}_{2}$ phases did not produce any appreciable increase of chromosome aberrations. Caffeine is reported to increase the number of X-ray-induced chromosome breaks in cultured leucocytes (Jacobson, cit. Kuhlmann et al. 1968). However, Wolff (1968) failed to demonstrate that caffeine inhibits the repair of X-ray-induced chromosome breaks in Vicia faba. Even on the assumption that caffeine synergizes the damage caused by the disintegration of incorporated ${ }^{3} \mathrm{H}$, the magnitude of the difference in the sensitivity between $S$ and $G_{1}$ phases can not be fully explained.

It is of particular interest that caffeine, in contrast to the other chromosome-breaking agents, rarely induces exchange aberrations. This indicates that the caffeine-induced breaks are not repaired. Caffeine essentially causes discontinuity of chromosome material, and therefore chromosome aberrations recovering in the second or more advanced divisions after exposure are expected to be of the terminal deletion type, in which a certain amount of chromosome material is missing. This has been clearly demonstrated in the present experiments. Recently considerable evidence has been accumulated in favor of the idea that chromosomal imbalance plays an important role in cell lethality in vivo. Recent studies on the fate of radiation-induced chromosome aberrations in human lymphocytes exposed in vivo (Buckton et al. 1962; Norman et al. 1966; Sasaki and Norman 1967) and in germ cells of laboratory animals exposed at their spermatogonial stage (Leonard 1970) show that the cells with unstable chromosome aberrations such as asymmetric exchanges and acentric fragments do not survive cell divisions, 
while only the cells with symmetric exchanges can survive. Since, caffeine induces chromosome aberrations predominantly of the unstable type, i.e., chromatid breaks, there is no way for these cells to survive cell divisions due to the genetic imbalance caused by the abnormal distribution of genetic material to the daughter cells, and therefore in most cases only cells with reasonably normal chromosome constitution may recover after mitosis. The viability of cells with chromosomal changes may depend on the amount of the genetic material lost, genetic significance of the lost part in the normal functioning of the cells, or tolerance to the cells carrying chromosomal changes within the in vivo system. Moreover, the present finding indicates that the induction of damage by caffeine is confined to the DNA-synthesis phase, cells in $\mathrm{G}_{1}$ phase not being susceptible. It is thus tempting to relate these lines of evidence to the ineffectiveness of caffeine at inducing abnormalities of the meitotic chromosomes at diakinesis in treated male mice (Adler 1966; Adler and Röhrborn 1969) and also to the ambiguous results on the induction of dominant lethal mutations in mice (Kuhlmann et al. 1968; Röhrborn 1968; Adler 1969; Epstein 1970). However, further experimental insight into the role of irreparable damage to the genetic material and the related genetic consequences is obviously needed.

\section{SUMMARY}

Caffeine induced a high frequency of chromatid aberrations in the cultured human leucocytes and the human embryonic cells in culture. The chromatid aberrations were predominantly gaps and breaks, and no exchange aberrations were observed. Experiments made by varying the interim between treatment and fixation, accompanied by the ${ }^{3} \mathrm{H}-\mathrm{TdR}$ labelling technique, showed that induction of damage was confined to the DNA-synthesis phase, in which the later part of the $\mathrm{S}$ phase was the most sensitive. Caffeine had no effect on the $G_{1}$ and $G_{2}$ phases. The rarity of exchange aberrations and the restriction of sensitivity to the DNA-synthesis phase may relate to the ambiguous results on the effectiveness of caffeine in the induction of dominant lethal mutations in laboratory animals.

\section{ACKNOWLEDGMENTS}

I am deeply indebted to Prof. A. Tonomura and Dr. M.S. Sasaki, under whose direction this work has been carried out, and their colleages in the Department of Human Cytogenetics, Tokyo Medical and Dental University. I am also grateful to Prof. H. Nishimura, the Department of Anatomy, Faculty of Medicine, Kyoto University, for his encouragement during the progress of this work and to others who have cooperated in supplying specimens.

This work was supported by grants from the National Institute of Child Health and Human Development (HD-01401) and the Association for the Aid of Crrippled Children, New York. 


\section{LITERATURE CITED}

Adler, I. D., 1969 Does caffeine induce dominant lethal mutations in mice? Humangenetik 7: 137148.

Adler, I.D., 1970 The problem of caffeine mutagenicity. In "Chemical Mutagenesis in Mammals and Man” (F. Vogel and G. Röhrborn, eds.) pp. 383-403, Springer-Verlag, Berlin, Heidelberg, New York.

Adler, I.D., and Röhrborn, 1969 Cytogenetic investigation of meiotic chromosomes of male mice after chronic caffeine treatment. Humangenetik 8: 81-85.

Buckton, K. E., P. A. Jacobs, W. M. Court Brown, and R. Doll, 1962 A study of the chromosome damage persisting after X-ray therapy for ankylosing spondylitis. Lancet 11: 676-682.

Demerec, M., G. Bertani, and J. Flint, 1951 A survey of chemicals for mutagenic action on $E$. coli. Amer. Naturalist 85: 119-136.

Epstein, S., 1970 The failure to induce mutagenic effects or to synergize the effects of known mutagens in mice. In "Chemical Mutagenesis in Mammals and Man" (F. Vogel and G. Röhrobor, eds.), pp. 404-419, Springer-Verlag, Berlin, Heidelberg, New York.

Gezelius, K., and N. Fries, 1952 Phage resistant mutants induced in E. coli by caffeine. Hereditas 38: 112-114.

Kuhlmann, W., H.G. Fromme, E. M. Heege, and W. Ostertag, 1968 The mutagenic action of caffeine in higher organisms. Cancer Res. 28: 2375-2389.

Leonard, A., 1970 Radiation-induced translocations in spermatogonia of mice. Mutation Res., 11: 71-88.

Moorhead, P.S., P.C. Nowell, W. J. Mellman, D. M. Battips, and D. A. Hungerford, 1960 Chromosome preparations of leukocytes cultured from human peripheral blood. Exptl. Cell Res. 20: 613-616.

Norman, A., M.S. Sasaki, R.E. Ottoman, and A.G. Fingerhut, 1966 Elimination of chromosome aberrations from human lymphocytes. Blood 27: 706-714.

Novick, A., 1956 Mutagens and antimutagens. Brookhaven Symp. Biol. 8: 202-216.

Novick, A., and L. Szilard, 1951 Experiments on spontaneous and chemically induced mutations of bacteria growing in the chemostat. Cold Spr. Harb. Symp. Quant. Biol. 16: 337-343.

Ostertag, W., 1966 Koffein-und Theophyllinmutagenese bei Zell- und Leukozytenkulturen des Menschen. Mutation Res. 3: 249-267.

Ostertag, W., E. Duisberg, and M. Stürmann, 1965 The mutagenic activity of caffeine in man. Mutation Res. 2: 293-296.

Ostertag, W., und B. J. Greif, 1967 Die Erzeugung von Chromatidenbrüchen durch Coffein in Leukocytenkulturen des Menschen. Humangenetik 3: 283-294.

Röhrborn, G., 1968 Mutagenicity test in mice. I. The dominant lethal method and the control problem. Humangenetik 6: 345-364.

Sasaki, M.S., and A. Norman, 1967 Selection against chromosome aberrations in human lymphocytes. Nature 214: 502-503.

Wolff, S., 1968 "Lecture at the Genetics Division of the National Institute of Radiological Sciences, Chiba, Japan", Sept. 1968. 